\title{
Validation of the GRAPE single view aerosol retrieval for ATSR-2 and insights into the long term global AOD trend over the ocean
}

\author{
G. E. Thomas ${ }^{1}$, C. A. Poulsen ${ }^{2}$, R. Siddans ${ }^{2}$, A. M. Sayer ${ }^{1}$, E. Carboni ${ }^{1}$, S. H. Marsh ${ }^{1, *}$, S. M. Dean ${ }^{1, * *}$, \\ R. G. Grainger ${ }^{1}$, and B. N. Lawrence ${ }^{2}$ \\ ${ }^{1}$ Atmospheric, Oceanic and Planetary Physics, University of Oxford, Oxford, UK \\ ${ }^{2}$ Space Science and Technology Department, Rutherford Appleton Laboratory, Didcot, Oxfordshire, UK \\ * present address: Department of Medical Physics and Bioengineering, Christchurch Hospital, New Zealand \\ ** present address: National Institute of Water and Atmospheric Research, Wellington, New Zealand
}

Received: 24 June 2009 - Published in Atmos. Chem. Phys. Discuss.: 14 October 2009

Revised: 22 March 2010 - Accepted: 11 May 2010 - Published: 26 May 2010

\begin{abstract}
The Global Retrieval of ATSR Cloud Parameters and Evaluation (GRAPE) project has produced a global dataset of cloud and aerosol properties from the Along Track Scanning Radiometer-2 (ATSR-2) instrument, covering the time period 1995-2001. This paper presents the validation of aerosol optical depths (AODs) over the ocean from this product against AERONET sun-photometer measurements, as well as a comparison to the Advanced Very High Resolution Radiometer (AVHRR) optical depth product produced by the Global Aerosol Climatology Project (GACP).

The GRAPE AOD over ocean is found to be in good agreement with AERONET measurements, with a Pearson's correlation coefficient of 0.79 and a best-fit slope of $1.0 \pm 0.1$, but with a positive bias of $0.08 \pm 0.04$. Although the GRAPE and GACP datasets show reasonable agreement, there are significant differences. These discrepancies are explored, and suggest that the downward trend in AOD reported by GACP may arise from changes in sampling due to the orbital drift of the AVHRR instruments.
\end{abstract}

\section{Introduction}

Atmospheric aerosols play an important role in determining the Earth's radiative balance, both through their absorption and scattering of radiation (the so-called direct aerosol effect, Yu et al., 2006) and through their influence on cloud proper-

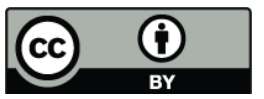

Correspondence to: G. E. Thomas (gthomas@atm.ox.ac.uk) ties (indirect effects Lohmann and Feichter, 2005). Aerosol effects remain one of the primary uncertainties in our understanding of the climate system (IPCC, 2007), so an understanding of the global aerosol distribution and its evolution over time are vital for improving our ability to characterise and predict the climate's response to anthropogenic activity.

Remote sensing of aerosol properties from imaging satellite radiometers is key in providing a global picture of the role of atmospheric aerosol. Although in situ and ground based measurements of aerosol can provide a very detailed picture of aerosol properties in a given location, satellite remote sensing is currently the only method by which a truly global measure of the distribution and evolution of aerosol on a continuous and timely basis can be obtained. Although there are now many such products available (Veefkind et al., 1998; Mishchenko et al., 1999; Martonchik et al., 2002; von Hoyningen-Huene et al., 2003; Remer et al., 2005; Grey et al., 2006), most do not cover the period before 2000 and thus are currently of limited use in investigating long term changes. In addition, the limited amount of information available from passive radiometers, combined with the large number of factors which influence the top of atmosphere signal, mean that the retrieval of aerosol properties using such instruments must rely on many assumptions about both the nature of the aerosol (composition, size distribution, height distribution and mixing state, for instance) and surface/atmospheric parameters (e.g. surface reflectance, atmospheric trace-gas concentration). These assumptions reduce the accuracy of aerosol retrievals in general and mean that no one algorithm or instrument can provide accurate estimates of aerosol loading in all situations, leading to disagreement

Published by Copernicus Publications on behalf of the European Geosciences Union. 
between different satellite based products. To provide an accurate picture of global atmospheric aerosol loading and evolution there is a need for further well-characterised satellite aerosol products, particularly if they improve the aerosol record prior to the current century.

The Along Track Scanning Radiometer (ATSR) series of instruments ${ }^{1}$ are ideally suited to meeting this need. These instruments can provide a nearly continuous record of aerosol properties from 1995, giving continuity to the end of the next decade with the Sea and Land Surface Temperature Radiometer (SLSTR). This paper characterises the aerosol optical depth (AOD) derived from ATSR-2 as part of the Global Retrieval of ATSR Cloud Parameters and Evaluation (GRAPE) project, which provides AOD and effective radius from 1995-2001. Descriptions of the instrument, the GRAPE product and the retrieval scheme are given in Sect. 2, while the AOD over ocean is validated against the Aerosol Robotic Network (AERONET) of sun photometers in Sect. 3. Section 4 compares the GRAPE AOD over ocean with the Global Aerosol Climatology Project (GACP) AOD product derived from the Advanced Very High Resolution Radiometer (AVHRR) instruments and provides insights in the long term trend in global mean AOD evident in the GACP dataset.

\section{Instrument and Algorithm descriptions}

\section{$2.1 \quad$ ATSR-2}

ATSR-2 (Mutlow et al., 1999) was successfully launched on board the second of the European Space Agency's Environment Research Satellites (ERS-2) on the 21st of April 1995. The primary object of the instrument was the continuation of the high-accuracy sea surface temperature (SST) record begun with the ATSR-1 instrument in 1991. ATSR-2 ceased operation in 2008, but pointing difficulties due to gyro failure on the ERS-2 satellite meant that post 2001 data only became readily available in the past year. A successive similar instrument, Advanced ATSR (AATSR), was launched on board Envisat in March 2002 and is expected to operate until 2012. AATSR will itself be superseded by the Sea and Land Surface Temperature Radiometer (SLSTR), which is due to be launched aboard the Sentinel-3 platform in 2014.

The ATSR-2 instrument has seven channels at $0.55,0.67$, $0.87,1.6,3.7,11.0,12.0 \mu \mathrm{m}$ and measures a $512 \mathrm{~km}$ swath orthogonal to the satellite's direction of flight, with a nadir view resolution of $1 \times 1 \mathrm{~km}$. The distinguishing feature of the ATSR series of instruments is their so-called dual-view system. The instrument uses a rotating scan mirror to sample radiance in a swath centred directly below the satellite (known as the nadir view) and a second view angled at approximately $55^{\circ}$ from vertical in the direction of the satellite's orbit (the

\footnotetext{
${ }^{1}$ Excluding the first example, ATSR-1, which lacked channels in the visible
}

forward view). This results in two measurements of each location, with atmospheric path lengths which differ by a factor of two. This measurement system is key (along with the more traditional 11 and $12 \mu \mathrm{m}$ split-window method) to producing the high precision SST measurements that are the primary aim of the instruments. The dual-view system has also been widely used to separate atmospheric and surface contributions to the top of atmosphere (TOA) signal when using ATSR-2 and AATSR to retrieve aerosol and surface properties (Veefkind et al., 1998; Grey et al., 2006; Thomas et al., 2009a).

The instrument was designed to have exceptional long term sensitivity and stability of calibration. For thermal calibration the ATSR instruments have two on-board black bodies at known temperatures. Radiation from these is measured during each scan and used to provide a continuous re-calibration of the instrument. This makes it possible to determine single channel equivalent temperatures correct to $\pm 0.05 \mathrm{~K}$. The shortwave channels of the instruments are calibrated by viewing solar radiation through an opal diffuser once an orbit. The ATSR-2 instrument has also been vicariously calibrated (Smith et al., 2002), showing that measured visible channel radiance is accurate to better than $4 \%$ and the infrared channels to better than $0.05 \mathrm{~K}$.

\subsection{GRAPE}

The GRAPE project has produced a 5 year (June 1995January 2001) climatology of aerosol and cloud properties from ATSR-2. Both cloud and aerosol properties were retrieved using the Oxford-RAL Aerosol and Cloud (ORAC) algorithm (Thomas et al., 2009b). The aerosol products produced are aerosol optical depth at $0.55 \mu \mathrm{m}$ and effective radius. The cloud products are: cloud top temperature, pressure and height, cloud fraction, optical depth, effective radius, phase (water or ice) and liquid water path. The resolution of the data in this data set is $\sim 4 \mathrm{~km}$. GRAPE version 3 AOD is validated in this paper ${ }^{2}$. Although the GRAPE project is now complete, development of the product is ongoing under the support of the NERC National Centre for Earth Observation (NCEO). This will include the processing of the post 2001 ATSR-2 data and AATSR data with the GRAPE version 3 algorithm.

\subsection{The ORAC retrieval algorithm}

The ORAC aerosol retrieval used in GRAPE is described in detail by Thomas et al. (2009b), but is summarised here for completeness. The algorithm is an optimal estimation scheme designed to allow the retrieval of aerosol properties from nadir (or near-nadir) viewing satellite radiometers. The

\footnotetext{
${ }^{2}$ GRAPE was a UK Natural Environment Research Council (NERC) project. The full GRAPE data-set is available for use from the British Atmospheric Data Centre. See http://badc.nerc.ac.uk/ data/grape/ for further details.
} 
aerosol retrieval used in this study is a development of the Enhanced Cloud Processor developed by Watts et al. (1998). The retrieval utilises the Levenberg-Marquardt algorithm to fit modelled radiances to the satellite measurements in a combination of visible/near infrared channels. The optimal estimation framework provides several advantages over other, more ad hoc methods. In particular

- The scheme fits all retrieved parameters to all measurement channels simultaneously, ensuring optimal use of the information contained within the measurements.

- A priori information can be incorporated into the scheme in a rigorous way, allowing the retrieval to be constrained by existing knowledge.

- The scheme provides full covariant error characterisation, allowing uncertainties in the measurement, a priori constraints and forward model assumptions to be propagated through to uncertainty estimates in the retrieved parameters.

- In addition to the error propagation, the scheme also provides statistics which can be used to identify poorly constrained or poorly fit retrievals. The primary of these is the cost function, which is a measure of how consistent the retrieved parameters are within the measurement and a priori constraints.

Although ORAC retrieves aerosol over both land and ocean, the quality of the AOD retrievals over land in the GRAPE product are known to be poor for reasons detailed in this section. In addition, the analysis undertaken by Thomas et al. (2009b) showed that, in the configuration used in GRAPE, the ORAC retrieval has limited sensitivity to aerosol effective radius. This paper therefore only presents an analysis of AOD over ocean.

The forward model uses TOA reflectance and atmospheric transmission look up tables (LUTs) calculated using the plane-parallel DIScrete Ordinates Radiative Transfer (DISORT) code (Stamnes et al., 1988). The LUTs account for both gas absorption (as given by MODTRAN (Berk et al., 1998) for a single reference atmosphere) and Rayleigh scattering. The GRAPE project uses a predefined geographical distribution of differing aerosol types, based on those described in the Optical Properties of Aerosols and Clouds (OPAC) database (Hess et al., 1998). The aerosol types and geographical distribution used in GRAPE are shown in Fig. 1 and their microphysical properties are summarised in Table 1 . These types define the optical properties and a priori effective radius (through their size distribution) used in the retrieval. It is clear that the use of this simple, fixed aerosol type climatology is a limitation of the GRAPE aerosol product, since it cannot hope to capture the highly diverse and variable properties of aerosol, particularly in regions periodically influenced by strong sources (e.g. the west coast of Africa). However, in the case of the GRAPE product,
Table 1. Properties of the aerosol types used in the GRAPE aerosol product (taken from Hess et al., 1998). The abbreviations nuc., acc. and coa. refer to the nucleation, accumulation and coarse modes, while tra. is short for transported. Note that the listed effective radius defines the a priori effective radius in the retrieval. In the retrieval this is varied by altering the number mixing ratio of the components which make up the class.

\begin{tabular}{lcll}
\hline Class & $\begin{array}{c}\text { Effective } \\
\text { radius } \\
(\mu \mathrm{m})\end{array}$ & $\begin{array}{l}\text { Components } \\
\text { Components }\end{array}$ & $\begin{array}{l}\text { Number } \\
\text { mixing ratio }\end{array}$ \\
\hline $\begin{array}{l}\text { Continental } \\
\text { average }\end{array}$ & 0.20 & water soluble & 0.314 \\
insoluble & $1.2 \times 10^{-5}$ \\
Desert dust & 1.26 & soot & 0.542 \\
& & water soluble & 0.87 \\
& & mineral(nuc.) & 0.117 \\
maritime & 0.85 & mineral(acc.) & $1.33 \times 10^{-2}$ \\
clean & & water soluble & $6.17 \times 10^{-5}$ \\
& & sea salt(acc.) & 0.987 \\
Arctic & 0.20 & water soluble & $\begin{array}{l}0.19 \times 10^{-2} \\
\end{array}$ \\
& & insoluble & $1.52 \times 10^{-6}$ \\
& & sea salt(acc.) & $2.88 \times 10^{-4}$ \\
& & soot & 0.803 \\
Antarctic & 0.40 & sulphate & 0.998 \\
& & sea salt(acc.) & $1.09 \times 10^{-3}$ \\
& & mineral(tra.) & $1.23 \times 10^{-4}$ \\
\hline
\end{tabular}

the measurements do not contain enough information to distinguish different aerosol types. The use of more complex aerosol climatologies for setting the aerosol types in GRAPE have been trialed, but it was found that they did not noticeably improve the quality of the product and resulted in retrieval artifacts along boundaries between different aerosol types.

In order to produce LUTs which are a function of aerosol effective radius, the size distribution of the aerosol types are perturbed by varying the mixing ratios of the different components which make up each aerosol type from the values prescribed in OPAC. Mie code (Grainger et al., 2004) is then used to convert the microphysical properties (size distribution and refractive index) of the perturbed aerosol classes into optical properties. The retrieval of aerosol effective radius thus not only implies a change in the size of the aerosol particles, but in the overall composition of the aerosol type. See Thomas et al. (2009b) for a more detailed description of the implication of this methodology. Due to the lack of ground truth data to compare against, aerosol effective radius is not validated in this paper. AERONET does provide effective radius as a parameter in its all-sky retrievals (Dubovik et al., 2002), but the sparcity of these measurements would require the use of modelled aerosol fields to interpolate between the two datasets and remains a task for further study. 

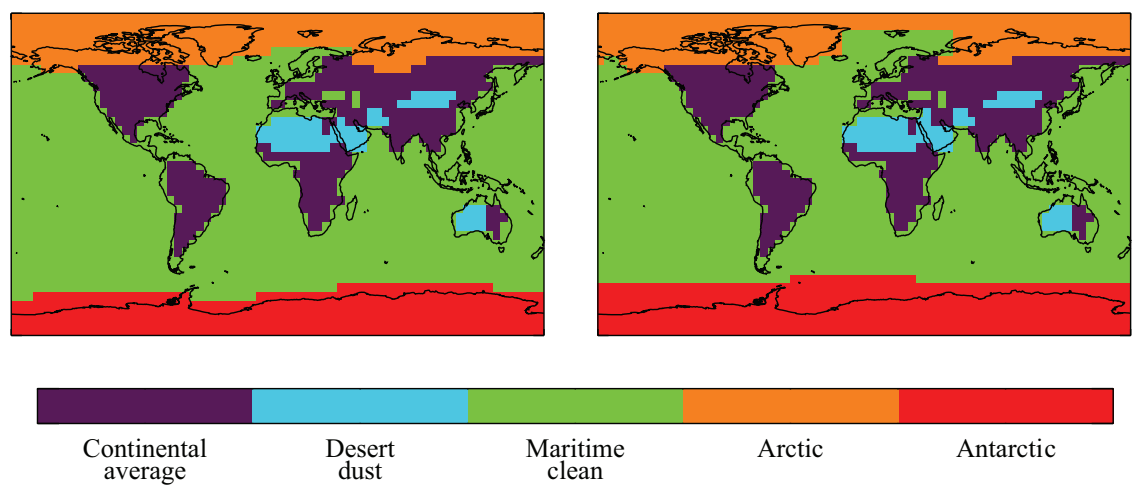

Fig. 1. The spatial distribution of aerosol types used by GRAPE. The left map shows the distribution used for Southern Hemisphere summer (October-March), the Northern Hemisphere summer (April-September) is given on the right.

Over the ocean the scheme uses surface reflectances based on an ocean reflectance model based on the Cox and Munk (Cox and Munk, 1954) algorithm for ocean surface roughness with a wind correction proposed by Watts et al. (1996), driven by wind fields from European Centre for Medium-range Weather Forecasting (ECMWF) reanalysis data. Over land the MODerate resolution Imaging Spectrometer (MODIS) surface Bi-Directional Reflectance Distribution Function (BRDF) product, MOD43B, (Jin et al., 2003) is used to define the surface reflectance. As the MODIS BRDF product is only available from 2000 onwards, data for the equivalent date and location from 2002 are used for all years. Errors resulting from this approximation are a major limiting factor to the accuracy of the GRAPE aerosol product over land and a primary reason that comparisons are limited to retrievals over the ocean in this paper.

The primary parameters retrieved by ORAC are aerosol optical depth at $0.55 \mu \mathrm{m}$ and effective radius. In addition, the algorithm allows small changes in the overall surface reflectance, although the spectral shape of the surface is fixed. In GRAPE these parameters are retrieved from the 0.67, 0.87 and $1.6 \mu \mathrm{m}$ channels in ATSR-2's nadir view. Although ATSR-2 also has a $0.55 \mu \mathrm{m}$ channel, this is not utilised by GRAPE as it is often unavailable due to the low-data-rate modes imposed on ATSR-2 by the ERS-2 satellites telemetry limitations (Mutlow et al., 1999). The scheme's ability to retrieve the surface reflectance is limited due to the small number of measurements available to it. Thus, in addition to the spectral variation of the surface reflectance being fixed, its magnitude is also tightly constrainted to the a priori value. Thomas et al. (2009b) found that errors in the a priori surface reflectance of more than 0.01 could not be accurately corrected for by the retrieval.

It should be reiterated that the retrieval fits the modelled aerosol properties to the measured TOA reflectances in all channels simultaneously. Thus the retrieved $0.55 \mu \mathrm{m}$ AOD will be just as accurate as a retrieval of, for instance, $0.67 \mu \mathrm{m}$ AOD would be, even though the $0.55 \mu \mathrm{m}$ channel is not used in the retrieval.
Due to the lack of cloud masks in the ungridded level 1 reflectance/brightness temperature data used in the GRAPE project, the scheme used two cloud flagging algorithms to classify each instrument pixel as either cloud or aerosol before the radiance data was rebinned into the $3 \times 4$ instrumentpixel bins (which provides approximately square retrieval pixels which are $\sim 4 \times 4 \mathrm{~km}$ at nadir) used in the retrieval. Over the ocean a customised scheme based on threshold tests on 11 and $12 \mu \mathrm{m}$ brightness temperatures, spatial variability of these values and a threshold on the Normalised Vegetation Difference Index (NDVI, defined by the TOA reflectance ratio $\frac{R_{0.67}-R_{0.87}}{R_{0.67}-R_{0.87}}$, where the subscripts denote the wavelength band) was used. Over the land a local implementation of the scheme described by Birks (2004) was used, which uses two NDVI ratios between the 0.55 and $0.67 \mu \mathrm{m}$ as well as the 0.67 and $0.87 \mu \mathrm{m}$ channels. Only retrieval pixels which contained no instrument pixels determined to be cloudy by these flags were used in retrieving aerosol properties.

It should be noted that the version of ORAC used to produce the GRAPE dataset made the assumption of a Lambertian surface reflectance. As a result of this assumption, it is not possible to make use of the dual-view capability of the ATSR instruments, as it would lead to inconsistencies in the description of the surface reflectance in the two views. In addition, the GRAPE aerosol retrieval used a subset of the channels used in the cloud retrieval and, due to the complex 3-dimensional structure of clouds, a dual view cloud retrieval does not yet exist. Therefore the GRAPE aerosol product is derived from the nadir view only. Subsequent development of the ORAC algorithm has included a dual-view aerosol and surface reflectance retrieval (Thomas et al., 2009a) utilising a BRDF description of the surface reflectance, which has been applied to ATSR-2 and part of the GlobAEROSOL project (Portela et al., 2010). 
Table 2. Quality control applied to GRAPE level 2 aerosol data. Only retrievals which satisfy all of these tests are used in this analysis.

\begin{tabular}{lcl}
\hline Value & Criteria & Description \\
\hline Iterations & $>1$ & $\begin{array}{l}\text { The retrieval must have converged and not returned the a priori state } \\
\text { after one iteration. } \\
\text { Retrieval must be consistent with both measurements and a priori con- } \\
\text { straints (see Rodgers (2000) or Thomas et al. (2009b) for a definition of } \\
\text { this quantity). } \\
\text { A high retrieved surface reflectance is indicative of sun-glint contami- } \\
\text { nation. } \\
\text { A very large retrieved effective radius is indicative of cloud contamina- } \\
\text { tion. }\end{array}$ \\
$\begin{array}{l}\text { flectance } \\
\text { Effective radius }\end{array}$ & $<5 \mu \mathrm{mm}$.
\end{tabular}

\section{Validation against AERONET}

The primary aerosol property given by most satellite tropospheric aerosol products is the aerosol optical depth (AOD) at some visible wavelength, and it is the estimate of this quantity from GRAPE that is validated in this paper.

The AERONET is a globally distributed federation of ground based sun/sky photometers primarily designed for monitoring the column aerosol loading. The AERONET instrumentation and data analysis schemes are described by Holben et al. (1998). In this paper we compare the GRAPE AOD to AERONET Level 2, version 2 direct-sun AOD measurements. Direct-sun AOD measurements are known to have a high level of accuracy for typical atmospheric aerosol loadings, due to the weak dependence of the retrieval on assumptions about the atmospheric state, with the estimate of total error of 0.01-0.02 in the so-called triplet AOD measurements which make up the basic AERONET product (Holben et al., 2001). AERONET also imposes standardisation of instruments, calibration, processing, quality control and distribution, which make it the primary source of calibration data for satellite based aerosol products such as GRAPE.

When comparing AOD derived from satellite measurements with those from ground-based AERONET sun photometers it is necessary to make allowances for the very different spatial and temporal sampling of the two measurement systems. AERONET provides a high temporal resolution AOD time-series for a given location, while the satellite provides a series of spatially resolved measurements of the AOD field, often separated by several days. The method used in this study to ensure a valid comparison could be made between these two different measurement system was that presented by Ichoku et al. (2002) for the validation of MODIS AOD measurements. The method can be summarised by the following steps:

1. The closest GRAPE retrieval pixel (i.e. $4 \mathrm{~km}$ grid box) to the AERONET station is identified.

2. Retrieval pixels which contain valid AOD values (i.e. are not flagged as cloud and pass the quality control cri- teria given in Table 2), are over the sea and lie within \pm 5 pixels $(\sim 20 \mathrm{~km})$ from the central pixel identified in step 1, are extracted from the GRAPE data. This provides a spatial sample from the GRAPE product, similar in size to that used by Ichoku et al. (2002).

3. All AERONET measurements for the given station are extracted with time $\pm 30 \mathrm{~min}$ of the satellite overpass. Given a typical aerosol transport speed of $20 \mathrm{~km} / \mathrm{h}$, this is consistent with the $\sim 20 \mathrm{~km}$ spatial distance sampled from the satellite (where the assumption has been made that approximately half of the $20 \mathrm{~km}$ radius around the AERONET station sample lies over the sea).

4. The number of valid retrievals, mean and standard deviation of AOD from each of these samples are then used in the comparison. Unlike the monthly averaging performed for the analysis presented in Sect. 4, simple unweighted averaging was applied in this case, as the number of samples in each average were small and generally had consistent retrieved uncertainty estimates.

In addition to the sampling difference between the two datasets, there is no AERONET measurement at $0.55 \mu \mathrm{m}$ to compare with the GRAPE AOD. This has been addressed by interpolating a $0.55 \mu \mathrm{m}$ AERONET value using the Ångström exponent between the 0.50 and $0.87 \mu \mathrm{m}$ AERONET measurements.

In order to minimise the risk of the inclusion of spurious measurements in the intercomparison, it is important that both datasets have adequate quality checks applied. In the case of AERONET data, only Level 2 data (which has been visually inspected and quality assured) from a list of sites determined to be representative of their surrounding areas were used (S. Kinne, personal communication, 2006. See Kinne et al. (2003) for an explanation of the methodology used in selecting sites). Figure 2 shows the locations of the AERONET sites found to provide matches with the GRAPE data over the ocean using these criteria. In total there are 22 stations, concentrated in North America and Europe, 


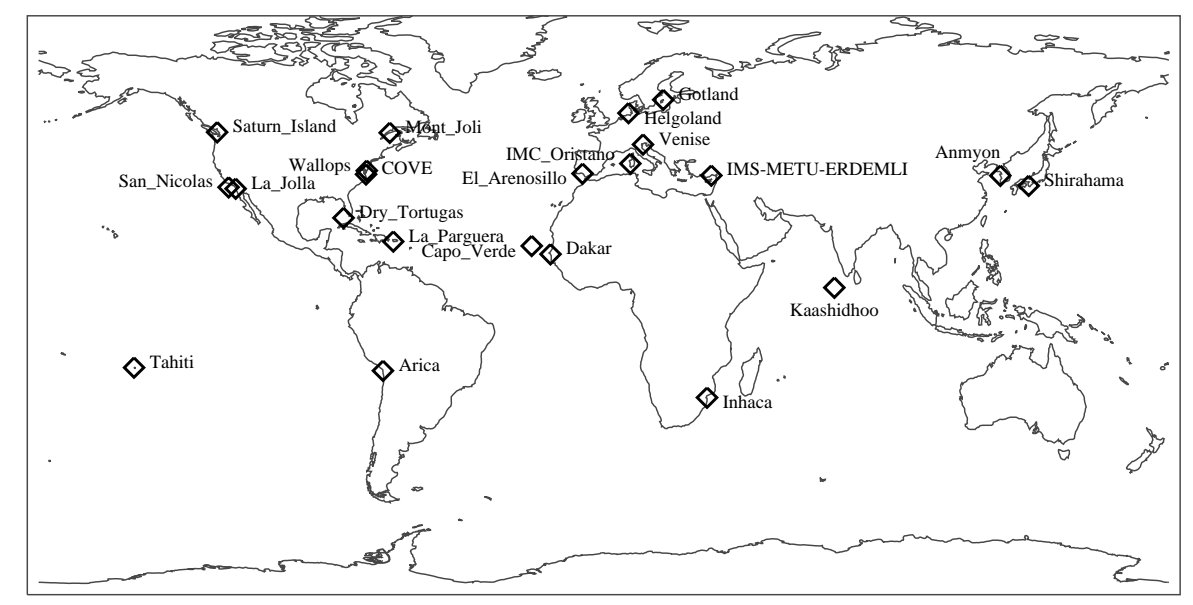

Fig. 2. Location of AERONET sites used for validation.

providing a total of 190 individual comparisons over the five year dataset.

The quality control applied to the GRAPE level 2 data are summarised in Table 2 . The tests reject retrievals which have not converged or where the forward-modelled TOA radiances are in poor agreement with those observed by the satellite, and remove data which show characteristics which are known to be indicative of conditions in which the retrieval will perform poorly. In addition, AERONET station overpasses where either the standard deviation of the values samples included in the temporal/spatial average AOD from either AERONET or GRAPE was greater than 0.1 were also rejected. A highly variable AOD field could result in strong sampling biases between the two measurements.

A scatter plot of the 190 matches between AERONET and GRAPE is given in Fig. 3. A weighted linear least-squares fit has been performed between the two datasets, taking the uncertainty (as characterised by the standard deviation of the data included in the spatio-temporal averaging described above) in both datasets into account (Press et al., 1992). This fit reveals that the GRAPE AOD data exhibit a positive bias of $0.08 \pm 0.04$ as compared to AERONET, although the slope of the fit is unity to a high level of confidence. The two datasets also show a strong Pearson's correlation coefficient, $r$, of 0.79 .

The optimal estimation framework of the GRAPE retrieval provides error estimates on a retrieval by retrieval basis, based on the propagation of measurement errors and estimates of errors introduced by approximations made in the forward model (Thomas et al., 2009b). If the retrieval were accounting for all sources of error, and errors in AERONET AODs were taken to be significantly smaller than those in the satellite retrievals, one would expect the differences between AERONET and GRAPE AODs to follow the PDF described by the GRAPE uncertainties. Figure 4 shows normalised histograms of the retrieved uncertainty in GRAPE

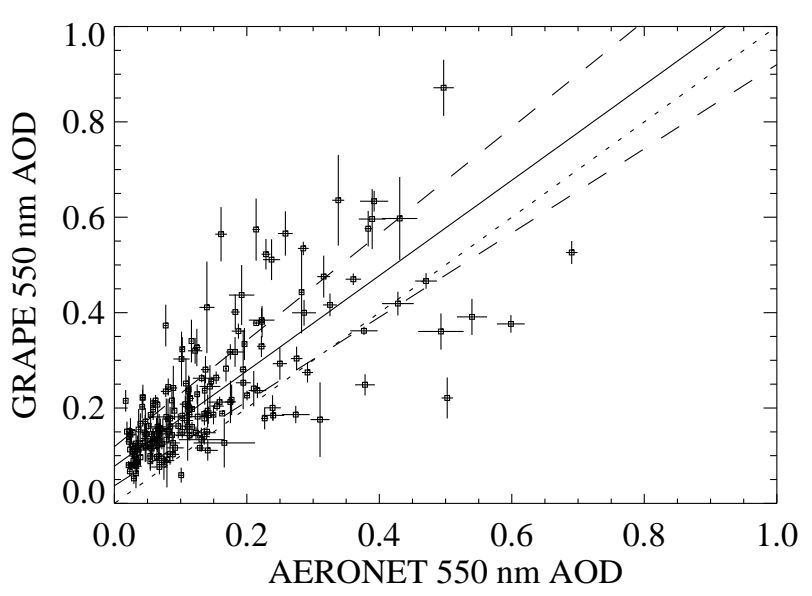

Fig. 3. AERONET comparison of ATSR- 2 with the sites shown in Fig 2. The two datasets have a Pearson correlation of 0.79 with an RMS difference of 0.13 . The best-fit line (solid line, $1 \sigma$ uncertainty given by dashed line) is given by the equation $\tau_{\mathrm{G}}=$ $(0.08 \pm 0.04)+(1.0 \pm 0.1) \tau_{\mathrm{A}}$. The one-to-one line (dotted) is also included for reference.

AODs for two days of data, as well as the histogram of the absolute difference between GRAPE and AERONET AODs. In this case the histogram of GRAPE uncertainties estimates can be taken as an upper limit on the expected errors in the values used in the AERONET comparison, since the spatial averaging over $n$ retrieval pixels applied to the data will reduce the random error by a factor of $\sqrt{n}$. However, it is clear that this error is still an underestimate of the true discrepancy with AERONET, although both distributions shown in Fig. 4 are well described by log-normal curves, both with standard deviation of 0.3. This suggests that a significant fraction of the scatter of points in seen in Fig. 3 can mostly be attributed to the random error in the GRAPE retrieval, with the offset 


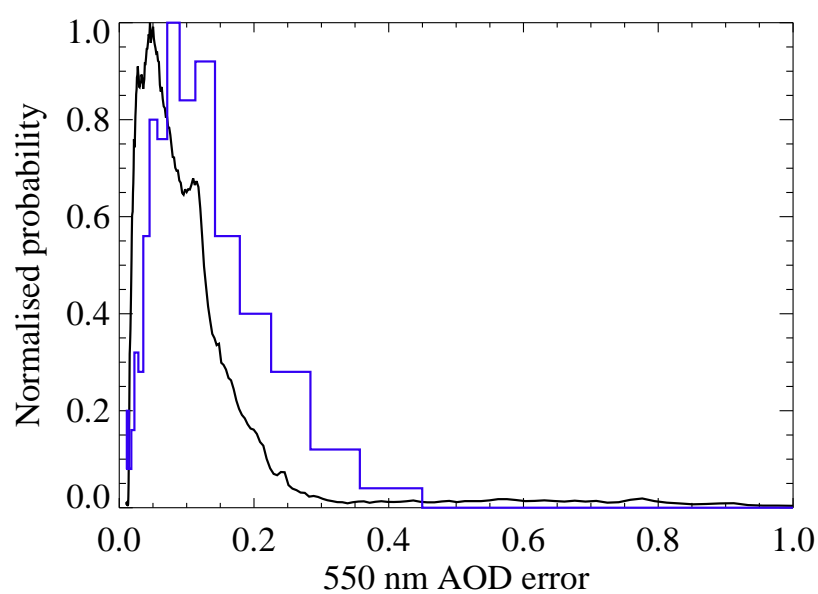

Fig. 4. Normalised histograms of the retrieved error in GRAPE AODs over the ocean (black line) and the discrepancy between GRAPE and AERONET AODs (blue line).

between the two distributions in Fig. 4 being a result of the apparent positive bias in GRAPE AOD values.

The reason for the positive bias in the GRAPE AODs is difficult to unambiguously determine. However, it could be a result of the fact that, by necessity, most of the GRAPE measurements included in this comparison are over coastal waters. The a priori ocean surface reflectance used in producing the GRAPE data assumes optical properties for typical deep-ocean water and a Fresnel reflection term as a function of surface wind-speed. The model does not take the effects of increased chlorophyll or gelbstoff loading. As the sediment and plankton loading of coastal waters is often substantial, it is likely that the assumed spectral shape of the surface reflectance is typically fairly poor in these areas, which would result in a bias in the retrieved AOD. In addition Thomas et al. (2009b) show that errors in the a priori absolute surface reflectance of 0.01 or more can also result in significant errors in the AOD retrieved by the GRAPE algorithm.

The other likely source of the observed offset are the aerosol optical properties assumed in the retrievals. The climatology of aerosol type used by GRAPE assigns the OPAC maritime-clean class to the majority of ocean pixels. However, since the majority of the AERONET comparisons are coastal, many of them will contain some retrievals using the aerosol type assigned to the neighbouring land mass, due to the coarse resolution of the map defining the spatial distribution of aerosol types (see Fig. 1).

The third possible cause of the positive bias seen in the GRAPE results is cloud contamination: i.e. the inclusion in the retrieval of pixels which, although not flagged as cloudy, either contain small amounts of sub-pixel cloud, or are effected by unmodelled 3-dimensional radiative effects from adjacent clouds. This is a relatively unlikely cause of the offset in this case however, since cloud contamination will gen- erally result in significantly elevated AODs, and thus would be expected to manifest itself more strongly in higher AOD points. This is not evident in the GRAPE AODs, which appear to show a fairly constant bias across the whole AOD range.

Table 3 shows the number of GRAPE-AERONET matches per site, with fit statistics for sites with a sample of size of at least ten overpasses. The tendency for GRAPE to overestimate the AOD compared to AERONET is again clear from these results, with the linear fit showing either a consistent bias (indicated by a positive intercept, $A$ ) or a slope greater than unity. Examination of the scatter plots for individual sites (which are omitted for brevity) and the $1 \sigma$ error estimates on the $A$ and $B$ parameters show that, as most stations are dominated by low AODs with only one or two values above $\sim 0.3$, the linear fits are generally poorly constrained. A good example of such a comparison in Table 3 is the Tahiti site, where both GRAPE and AERONET show optical depths of 0.1 or lower for all 20 matches, resulting in a low RMS of 0.05 , but a poor linear fit and low correlation.

The two notable exceptions in Table 3 are Capo_Verde (in the Cape Verde Islands) and Venise (located on the Acqua Alta Oceanographic Tower, off the coast of Venice). Both of these sites display a wide range of aerosol loading due to episodic transport from strong continental sources: these being wind blown Saharan dust in the case of Capo_Verde and industrial pollution from the Po Valley for Venise. Both sites also show a strong correlation between GRAPE and AERONET (0.94 and 0.96 respectively), but show quite different RMS and best-fit lines. Results from Capo_Verde the usual positive bias in GRAPE AODs compared to AERONET at low optical depths, but this is reversed at high optical depths, with GRAPE providing lower optical depths than AERONET. This is reflected in a slope of $<1$ in Table 3 . Venise results also show a small positive basis in GRAPE at low optical depth, but this bias increases with increasing AOD, resulting in a slope $>1$ in Table 3 .

These two results, although by no means conclusive, suggest that GRAPE AOD tends to be under-estimated in the case of wind blown dust (indicated by high Capo_Verde AODs), but over estimated in the presence of urban/industrial pollution (indicated by high Venise AODs). This cannot be considered a firm conclusion however, since problems accurately representing the surface reflectance (especially for the Venise site, where the ocean is shallow and enclosed by land on three sides) and separating clouds from aerosol (especially for Saharan dust outflow, where very high aerosol loading could easily be flagged as cloud) complicate the picture.

The Capo_Verde and Venise AERONET comparisons also suggest that, in addition to the random noise in the GRAPE product, the large scatter apparent in Fig. 3 might be largely explained by the inaccuracy of the aerosol properties assumed in the GRAPE retrieval. Such errors are most likely to manifest themselves at high AOD, as such events would 
Table 3. Statistics of comparisons between GRAPE and AERONET $550 \mathrm{~nm}$ AODs for each AERONET station. The values A and B are the coefficients of a weighted linear least squares fit like that shown in Fig. 3, such that $\tau_{g}=A+B \tau_{A} . r$ is the Pearson correlation coefficient and RMS is the root-mean-squared difference between the two data sets. Statistics are omitted for sites for which there were less than 10 overpasses.

\begin{tabular}{lrcccc}
\hline Station name & Matches & $A$ & $B$ & $r$ & RMS \\
\hline Anmyon & 1 & & & & \\
Arica & 14 & $0.1 \pm 0.1$ & $1.0 \pm 0.3$ & 0.67 & 0.10 \\
COVE & 8 & & & & \\
Capo_Verde & 14 & $0.1 \pm 0.1$ & $0.7 \pm 0.2$ & 0.94 & 0.10 \\
Dakar & 1 & & & & \\
Dry_Tortugas & 18 & $0.1 \pm 0.1$ & $0.4 \pm 0.3$ & 0.53 & 0.10 \\
El_Arenosillo & 5 & & & & \\
Gotland & 10 & $0.05 \pm 0.08$ & $1.8 \pm 0.4$ & 0.96 & 0.11 \\
Helgoland & 2 & & & & \\
IMC_Oristano & 8 & & & & \\
IMS-METU-ERDEMLI & 11 & $0.2 \pm 0.1$ & $0.9 \pm 0.3$ & 0.87 & 0.11 \\
Inhaca & 7 & & & & \\
Kaashidhoo & 7 & & & & \\
La_Jolla & 4 & & & & \\
La_Parguera & 4 & & & & \\
Mont_Joli & 1 & & & & \\
San_Nicolas & 22 & $0.06 \pm 0.07$ & $1.5 \pm 0.3$ & 0.64 & 0.09 \\
Saturn_Island & 15 & $0.1 \pm 0.1$ & $1.1 \pm 0.4$ & 0.58 & 0.11 \\
Shirahama & 3 & & & & \\
Tahiti & 14 & $0.0 \pm 0.1$ & $1.5 \pm 0.6$ & 0.38 & 0.05 \\
Venise & 20 & $0.1 \pm 0.1$ & $1.5 \pm 0.3$ & 0.96 & 0.24 \\
Wallops & 1 & & & & \\
\hline All & 190 & $0.08 \pm 0.04$ & $1.0 \pm 0.1$ & 0.79 & 0.13 \\
\hline
\end{tabular}

often be associated with aerosol with different characteristics to the maritime background being transported over the coast from continental sources.

\section{Intercomparison with GACP}

Although AERONET provides a ground-truth AOD measurement which allows the absolute accuracy of the GRAPE aerosol product to be assessed, it provides sparse spatial coverage, with large areas of the globe completely empty of measurements. Additionally, for the period of the GRAPE mission, the AERONET temporal coverage is generally quite sparse and does not offer much scope for time-series analysis on the data. In order to examine both the global distribution of AOD provided by GRAPE and its evolution through the five year dataset, a contemporary dataset with similar spatial and temporal coverage is required for comparison.

The Advanced Very High Resolution Radiometer (AVHRR) series of instruments are an ideal candidate to provide this comparative dataset, as they provide coverage throughout the GRAPE period and operate with similar spectral bands to ATSR-2. AVHRR measures the reflectance of the Earth in five relatively wide (in comparison with more recent satellite radiometers) spectral bands. These are centred around 0.6, 0.9, 3.7, 11 and $12 \mu \mathrm{m}$. The first AVHRR instrument lacked the $11 \mu \mathrm{m}$ channel, while the latest version (AVHRR/3) adds a channel at $1.6 \mu \mathrm{m}$. These instruments have been flown on a number of different platforms by the U.S. National Oceanic and Atmospheric Administration (NOAA), starting with the TIROS-N satellite in 1978. The latest versions of the instrument are carried on board the MetOp platform operated by EUMETSAT.

The AVHRR aerosol data used in this analysis are those produced by GACP (Geogdzhayev et al., 2002, 2005). GACP was a major research effort to produce a 23 -year global aerosol climatology compiled from a retrieval using the first two channels of AVHRR, supplemented with other data sets at later dates. The data is provided as monthly mean values on an equal angle $1 \times 1^{\circ}$ lat-lon grid. The retrieval used in GACP uses a direction set method to minimise an error function consisting of the weighted RMS differences between the measured radiances in channels 1 and 2 of AVHRR with LUTs of modelled radiances. These LUTs are generated by adding-doubling radiative transfer code and include a parameterisation of the ocean surface reflectance based on 
windspeed (the underlight and surface foam contributions to the signal are neglected), as well as gaseous absorption from ozone and water vapour (Mishchenko et al., 1999). The aerosol in the model uses a power-law size distribution of spherical particles with a fixed refractive index of $1.5-0.003 i$ in both channels (Geogdzhayev et al., 2005). The retrieved parameters are the AOD at $550 \mathrm{~nm}$ and the Ångström parameter (which is directly related to the exponent in the powerlaw describing the size distribution). GACP AODs have been validated against ship borne radiometers (Liu et al., 2004; Smirnov et al., 2006) and was found to have a Pearson correlation of 0.90 . The retrieval was found to slightly over estimate low AODs, with a linear fit between the ship based AODs, $\tau_{s}$, and the GACP retrievals, $\tau_{v}$, yielding $\tau_{v}=$ $0.047+0.836 \tau_{s}$. The time period covered by the GRAPE dataset is almost identical to that covered by the NOAA-14 AVHRR instrument in the GACP dataset.

GACP is one of two important aerosol retrievals developed for AVHRR, the second being the Pathfinder Atmosphere (PATMOS) algorithm (Stowe et al., 2002). Several variants of the PATMOS product have been developed and, although they are not included in this study, have been comprehensively compared with the GACP dataset (Zhao et al., 2008). Recently a decreasing trend in globally averaged AOD has been reported from both GACP (Mishchenko et al., 2007b) and PATMOS (Zhao et al., 2008).

In order to compare GRAPE and GACP data, the GRAPE AOD data have been composited into $1 \times 1^{\circ}$ monthly composites of the same form as the GACP data. This process was complicated by the fact that when one is combining large sets of data derived from an optimal estimation retrieval scheme, such as ORAC, simple averaging can produce a result that is biased towards the a priori value used in the retrieval. The result returned by an optimal estimation algorithm can be viewed as a mean of the fit to the measurements and the a priori estimate, weighted by the uncertainty in each:

$\frac{\tau}{\sigma^{2}}=\frac{\tau_{m}}{\sigma_{m}^{2}}+\frac{\tau_{a}}{\sigma_{a}^{2}}$

where $\tau$ is the retrieved estimate of AOD, with uncertainty $\sigma, \tau_{m}$ and $\sigma_{m}$ are the proportion of the retrieved value determined from the fit to the measurements, with its associated uncertainty, while $\tau_{a}$ and $\sigma_{a}$ are the a priori and its uncertainty. It is clear that if a simple mean is taken from $N$ samples of such data, where all retrievals use the same a priori (which is the case for AOD in the GRAPE retrieval), the a priori will receive $N$ times its correct weighting in the average. Generally, this effect will be negligible because Eq. (1) will be very heavily weighted towards the measurement information, but for large ensembles of data or for relatively poorly constrained retrieval results, it can become significant. The values for $\tau$ and $\sigma$ are products of the retrieval and, in the case of GRAPE, $\log _{10}\left(\tau_{a}\right)=-1.0 \pm 1.0$ (AOD is retrieved on a logarithmic scale by ORAC). Note also that, by definition

$$
\frac{1}{\sigma^{2}}=\frac{1}{\sigma_{m}^{2}}+\frac{1}{\sigma_{a}^{2}} \text {. }
$$

Combining Eqs. (1) and (2) we can derive the value of AOD defined by the fit to the measurements alone

$\tau_{m}=\frac{\left(\sigma \sigma_{a}\right)^{2}}{\sigma_{a}^{2}-\sigma^{2}}\left[\frac{\tau}{\sigma^{2}}-\frac{\tau_{a}}{\sigma_{a}^{2}}\right]$.

A weighted mean value for AOD, with the correct a priori weighting, can then be calculated using the expression

$\bar{\tau}=\frac{\left[\sum \frac{\tau_{m}}{\sigma_{m}^{2}}\right]+\frac{\tau_{a}}{\sigma_{a}^{2}}}{\left[\sum \frac{1}{\sigma_{m}^{2}}\right]+\frac{1}{\sigma_{a}^{2}}}$,

where the summations are over all the samples in the average.

Global maps of ATSR-2 (computed using Eq. 4) and GACP AOD, on the same $1 \times 1^{\circ}$ grid, are shown in Fig. 5, while Fig. 6 shows maps of the difference between the seasonal averages from each product. Both datasets show very similar patterns of AOD, with a level of agreement which compares favourably with other comparisons of satellite derived aerosol optical depth (Myhre et al., 2004, 2005; Kinne et al., 2003). A linear fit between the GACP and GRAPE $1 \times 1^{\circ}$ monthly values yields $\tau_{G}=-0.004+1.1 \tau_{v}$ (where $\tau_{v}$ is the GACP optical depth and $\tau_{G}$ refers to the GRAPE value, as earlier). Here only grid boxes for which GRAPE has retrieved an average AOD of less than 1.0 are included in the fit: as GACP has a maximum permitted AOD value of 1.0, this filtering is required to produce a fair point-by-point comparison. Thus, neglecting the lack of any AODs above 1.0 in GACP, there is little global bias between the two datasets. However Figs. 5 and 6 show clear systematic differences between the two datasets.

Firstly, GRAPE has some anomalously high optical depths at high latitudes. This is evidence of sea ice contamination of the GRAPE product, resulting in an a priori underestimate of surface reflectance and correspondingly poor retrievals. This is a known issue in the version 3 GRAPE product and will be corrected in later variants. It should also be noted that in the time-series analysis in Sects. 4.1 and 4.2, a point by point comparison was used, and thus did not include ice contaminated points from GRAPE (as these points are not present in the GACP data).

The GRAPE product also shows somewhat higher optical depths in many regions of continental outflow, particularly in the case of the Atlantic African biomass-burning plume and Asian plume across the Pacific. The seasonal bias between GACP and GRAPE AODs can be 0.2 or more near the continents, particularly during the northern hemisphere summer. Both products use aerosol properties optimised for maritime conditions in most of these locations (as mentioned in the previous section some GRAPE retrievals near 

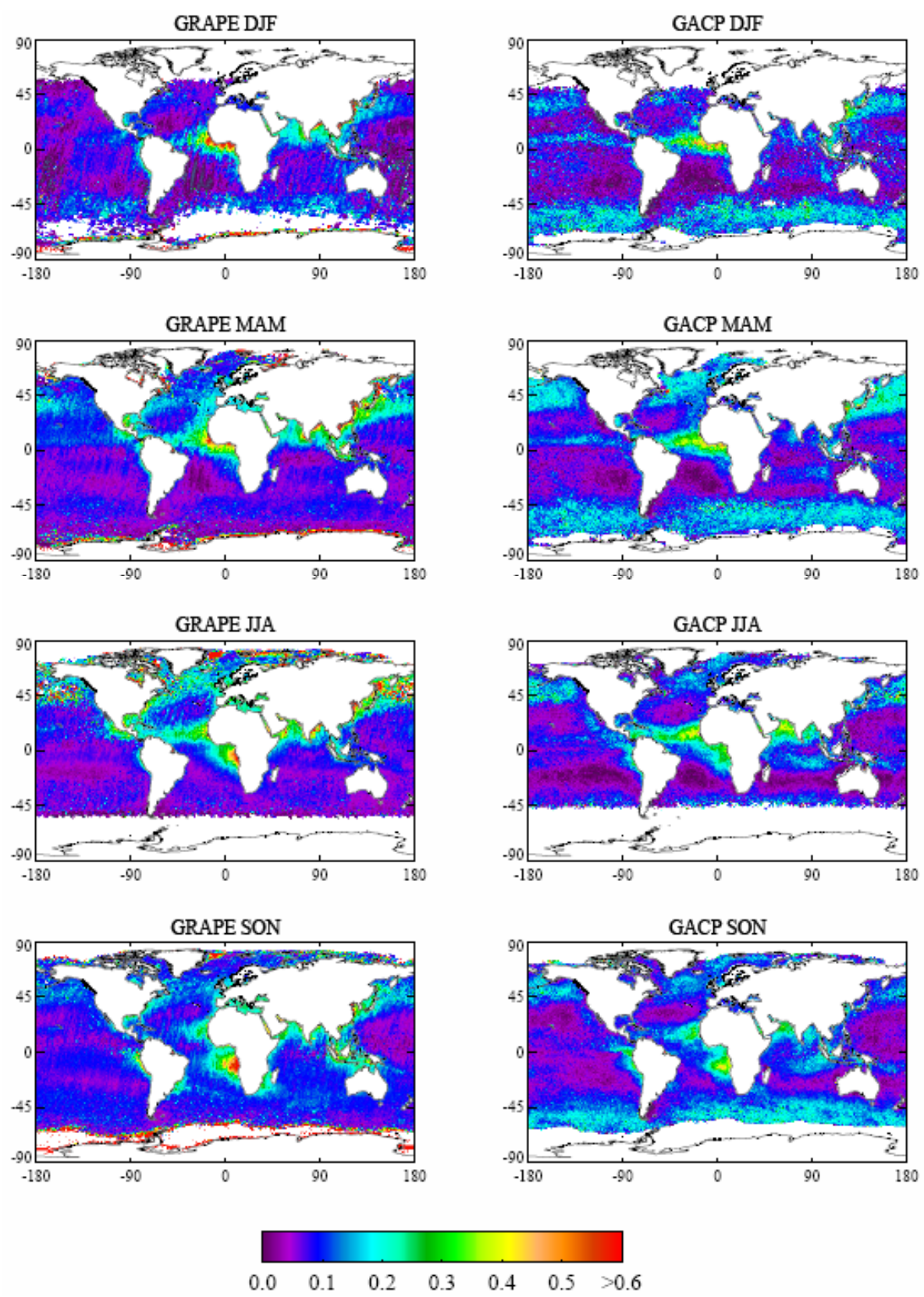

Fig. 5. Global seasonal maps of GRAPE and GACP AOD. Each plot shows the average of all monthly data, where both datasets are available. The seasons are defined as December-January-February (DJF), March-April-May (MAM) June-July-August (JJA) and September-OctoberNovember (SON).

the cost will use continental aerosol properties, but these will be in the minority), although the precise properties assumed are not the same in each product. Thus it is possible that discrepancies in optical depth between each product, especially systematic differences revealed by long term averaging, are a result of the difference in assumed aerosol properties. This hypothesis is further supported by the general latitudinal dependence of the systematic differences between the two products, where GACP AODs tend to be higher at high latitudes, while GRAPE AODs are generally higher at mid-latitudes. However, it is not only the assumed aerosol optical properties which could explain the discrepancies between the two datasets. Other a priori assumptions, most notably cloud clearing and surface reflectance, can easily result in even larger discrepancies than assumptions about the aerosol itself. However, with only $1 \times 1^{\circ}$ monthly GACP data available, it is not possible to identify the reasons behind such discrepancies with any confidence. 

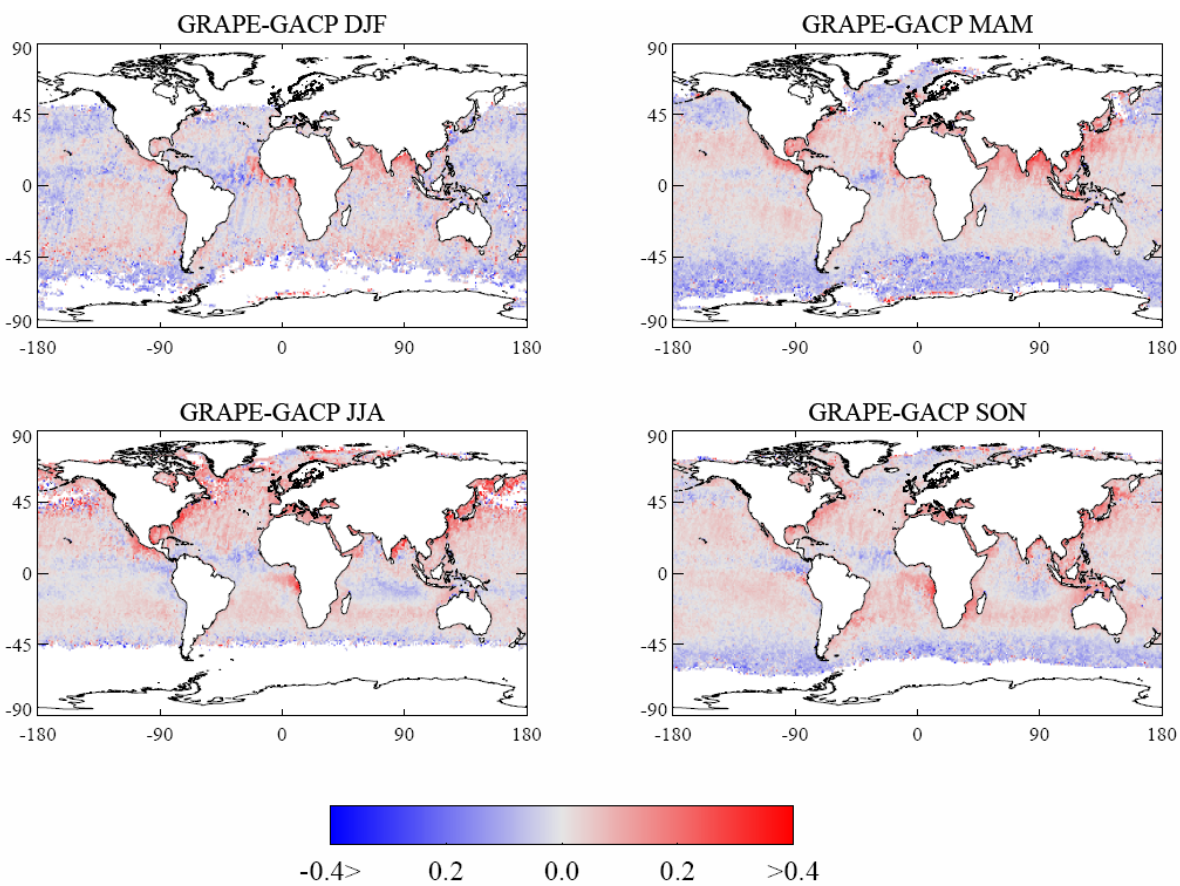

Fig. 6. The difference between GRAPE and GACP AOD for each of the seasonal maps show in Fig. 5.

The fact that, globally, there is little overall bias between the GRAPE and GACP products supports the suggestion that the positive bias seen in GRAPE AODs against AERONET is, at least partially, due to inaccuracies in modelling the surface reflectance of coastal waters (see Sect. 3). The bias seen in GACP results against ship-bourne AOD measurements of approximately 0.04 suggests a similar bias for GRAPE AODs over the remote ocean.

\subsection{Global time-series comparison}

To facilitate the investigation of the time-series of the two datasets, global mean ocean optical depths were calculated from the $1 \times 1^{\circ}$ GRAPE and GACP monthly fields described above. To ensure consistency, only grid boxes containing data from both instruments were included in the calculation of the averages. The results are shown in Fig. 7. In order to investigate trends in the two datasets, a five parameter equation has been fit to each time-series. The function used in the fit is given by Eq. (5) and consists of a linear trend superimposed on a sinusoid with a yearly period, with a linear trend in amplitude:

$y(t)=a_{0}+a_{1} t+\left(a_{2}+a_{3} t\right) \sin \left(\frac{t+a_{4}}{182.624}\right)$,

where $t$ is time in days, and $a_{i}$ are the fitted parameters. This function was chosen over a simple linear fit to the data to minimise the influence of the seasonal cycle ${ }^{3}$ on any apparent

\footnotetext{
${ }^{3}$ Which is especially strong in some regions, see Sect. 4.2
}

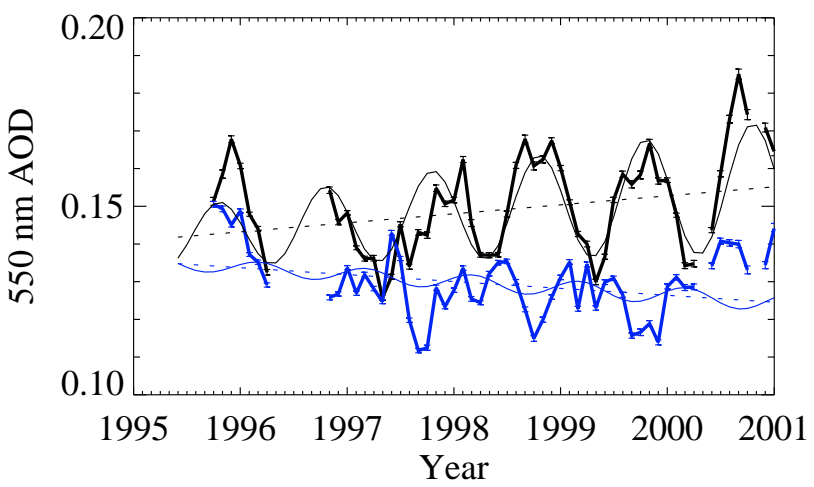

Fig. 7. Global time-series showing the comparison of AVHRR AOD with ATSR-2 AOD between 1995 and 2001. ATSR-2 data are shown in black and AVHRR in blue. The thick lines show the mean value for each month, with error bars indicating the standard error on the mean. Fits to the time-series using Eq. (5) are given by the thin solid lines, and the linear component of these fits are shown by the dotted lines.

multi-annual trend in the data. The fits using this equation are included in Fig. 7, as are the linear trend parts of the fits (i.e. $\left.a_{0}+a_{1} t\right)$.

Figure 7 shows a significant discrepancy between the two datasets, with GRAPE showing consistently higher AOD (with the difference being on the order of 0.01) and showing a positive trend, rather than the negative one consistently 
found in AVHRR analyses. This can be constrasted against the linear fit between the $1 \times 1^{\circ}$ monthly mean values given above, where no bias was found: the difference can be attributed to the inclusion of GRAPE AODs greater than 1.0 in the time-series averages. Additionally, the GRAPE data display a distinct yearly cycle, which is not present in the GACP data. This difference and the offset in the global mean AOD will be further discussed in the next section, but first the curve fitting will be described further.

The function given in Eq. (5) was fit using weighted least squares, with each point weighted by the standard error on the mean:

$\delta \bar{\tau}_{\mathrm{g}}=\frac{\sigma\left(\bar{\tau}_{\mathrm{g}}\right)}{\sqrt{n}}$,

where $\bar{\tau}_{\mathrm{g}}$ is the global mean value of AOD for a given month, calculated from $n$ samples, and $\sigma\left(\bar{\tau}_{\mathrm{g}}\right)$ is the associated standard deviation. One can propagate this error into an estimate of an error in each of the parameters in Eq. (5) using the gradient of this function with respect to that parameter:

$$
\frac{1}{\delta a_{i}^{2}}=\sum_{j=1}^{N}\left(\frac{\partial y}{\partial a_{i}}\right)^{2} \frac{1}{\delta \bar{\tau}_{\mathrm{g}, j}^{2}}
$$

where the right hand side is summed over the $N$ monthly global mean values in the time-series. However, this will produce an error estimate based on the assumption that the model fit to the data describes all the systematic variability in the data (i.e. that any differences between the data and fitted function are due solely to the random variability in the data described by the $\sigma\left(\bar{\tau}_{\mathrm{g}}\right)$ values). Since it is highly unlikely that the variability in the global mean AOD can be completely described by Eq. (5), these error estimates will clearly be an underestimate of the true uncertainly in the fitted parameters.

We address this problem by scaling the $\delta a_{i}$ values by the $\chi^{2}$ statistic for the fit, where $\chi^{2}$ is defined as

$\chi^{2}=\sum_{j}\left(\frac{y_{j}-\bar{\tau}_{\mathrm{g}, j}}{\sigma\left(\bar{\tau}_{\mathrm{g}, j}\right)}\right)^{2}$,

where $y_{j}$ are the fitted values of Eq. (5) for each monthly average $\bar{\tau}_{\mathrm{g}, j}$. In the case where $y_{j}$ and $\bar{\tau}_{\mathrm{g}, j}$ are samples from the same distribution with standard deviation $\sigma\left(\bar{\tau}_{\mathrm{g}, j}\right), \chi^{2}$ has the expectation value $N-M$, where $M=5$ is the number of parameters in Eq. (5) and $N$ is as defined above (i.e. the number of degrees of freedom for the fit). Thus, by rescaling the uncertainties on the parameters by

$\delta a_{i}^{\prime}=\sqrt{\frac{\chi^{2}}{N-M}} \delta a_{i}$,

we are effectively forcing the uncertainties in $a_{i}$ to reflect the true discrepancy between the data and model fit.
Following this procedure, we find that the linear component of the fit to the GRAPE data (the black dotted line in Fig. 7) is $\bar{\tau}_{\mathrm{g}}(t)=(0.142 \pm 0.002)+(6.5 \pm 2.0) \times 10^{-6} t$, where $t=0$ is defined to correspond to 1st June 1995, corresponding to the first point in the time-series. Similarly, the fit to GACP data is $\bar{\tau}_{\mathrm{g}}(t)=(0.135 \pm 0.003)-(5.0 \pm 2.4) \times 10^{-6} t$. It is worth noting that the decadal trend seen in the GACP data over the GRAPE data period $\left(0.018 \pm 0.009\right.$ decade $\left.^{-1}\right)$ is very close to that found by Mishchenko et al. (2007b) for the entire post Pinatubo eruption dataset. However, due to the relatively short time-span of GRAPE the trends in both datasets are not significant at the $99 \%$ confidence level, as was case for the trend found by Mishchenko et al.

\subsection{Regional time-series comparison}

The discrepancies between the two time-series in Fig. 7 can largely be attributed to regional differences between the two datasets, as well as the lack of any AODs greater than 1.0 in GACP. To investigate regional trends and differences between the two dataset, the ocean regions defined by Quaas et al. (2008) have been used. These regions are shown in Fig. 8 and the time-series for GACP and GRAPE data within these regions are given in Fig. 9. Equation (5) has again been fitted to the time-series to reveal long term trends in the data and the gradient of the trend line for each region is listed in Table 4.

Figure 9 reveals a complicated picture behind the differences seen in the global comparison; the level of agreement between the two datasets is clearly different for different regions:

- Both northern regions show a large discrepancy in the seasonal cycles between the two datasets, with GRAPE showing a much stronger cycle than is present in GACP. In both cases there is reasonable agreement between the two time-series during the low-AOD section of the GRAPE cycle, but then the GACP values drop away, while GRAPE continues to increase. It is interesting to note that GACP does show a strong seasonal cycle in the NPO, but it is approximately 3 months out of phase. The NPO is also notable in that the GRAPE data show an increasing trend (due to an increasing amplitude of the season cycle while the lower limit of the cycle remains approximately constant).

- The tropical oceans show little evidence of a season cycle, except for the TAO (which shows evidence of the cycle of African biomass burning). With the exception of the TIO, the two datasets show better overall agreement than in the northern oceans. It is also worth noting that the two most statistically significant increasing trends seen in the GRAPE data occur in the TIO and TPO. 
Table 4. Trends in $550 \mathrm{~nm}$ AOD, in units of decade ${ }^{-1}$, from regional time-series. The uncertainties are the $1 \sigma$ estimates propagated from the standard deviation of each point in the time-series.

\begin{tabular}{lcccc}
\hline Region & \multicolumn{2}{c}{ GRAPE } & \multicolumn{2}{c}{ GACP } \\
& Mean AOD & Trend & Mean AOD & \multicolumn{1}{c}{ Trend } \\
\hline Global & 0.151 & $0.024 \pm 0.007$ & 0.130 & $-0.018 \pm 0.009$ \\
NAO & 0.175 & $0.00 \pm 0.02$ & 0.132 & $-0.03 \pm 0.01$ \\
NPO & 0.169 & $0.04 \pm 0.02$ & 0.131 & $-0.01 \pm 0.01$ \\
TAO & 0.203 & $0.00 \pm 0.03$ & 0.187 & $0.03 \pm 0.03$ \\
TPO & 0.124 & $0.035 \pm 0.003$ & 0.111 & $-0.01 \pm 0.01$ \\
TIO & 0.173 & $0.05 \pm 0.01$ & 0.133 & $0.03 \pm 0.02$ \\
SAO & 0.120 & $0.01 \pm 0.01$ & 0.107 & $-0.06 \pm 0.02$ \\
SPO & 0.112 & $0.02 \pm 0.01$ & 0.112 & $-0.07 \pm 0.02$ \\
SIO & 0.129 & $0.02 \pm 0.01$ & 0.120 & $-0.09 \pm 0.02$ \\
\hline
\end{tabular}

- Overall, the southern oceans (SAO, SPO and SIO) show the best agreement between the two datasets. Both show a seasonal cycle of similar magnitude and phase and have similar mean values. However, GACP shows a negative trend in all three regions, but this is not present in the GRAPE data.

Perhaps the most surprising difference between the GACP and GRAPE time-series is the negative trend seen in the GACP southern ocean results. The presence of a decreasing trend in AOD in the Southern oceans is a surprising result since the aerosol burden in these regions is primarily generated by wind driven spray and phytoplankton-generated dimethyl sulphide (DMS) from the ocean surface.

Time-series of daily mean $10 \mathrm{~m}$ altitude wind speed from ECMWF reanalysis data and monthly mean chlorophyll$a$ concentration from the GlobCOLOUR dataset (Pinnock et al., 2007), for the combined SAO, SPO and SIO regions, are shown in Fig. 10. The wind speed shows a slight increasing trend of $0.028 \pm 0.005 \mathrm{~ms}^{-} 1$ decade $^{-1}$, but this only amounts to a $0.2 \%$ change in the average wind speed over the 5 years. Although GlobCOLOUR data only becomes available towards the end of 1997 (with the launch of the SeaWIFS instrument), there is no significant trend apparent in the data $\left(-0.01 \pm 0.04 \mathrm{mg} \mathrm{m}^{-3}\right.$ decade $\left.^{-1}\right)$. Thus, it seems unlikely that the AOD trend found in GACP data can be attributed to changes in the wind speed or ocean ecosystem.

At high latitudes satellite radiometers are susceptible to temporal sampling biases. In the winter months, the highlatitude limits of the northern, or southern, regions will be truncated by the solar zenith angle limits of the retrievals $\left(80^{\circ}\right.$ in the case of GRAPE). This will introduce a cyclical sampling bias into both datasets, which could result in an spurious seasonal cycle in the mean AOD. Figure 11 shows the latitude limits of both datasets throughout the period of comparison. In the case of the GRAPE dataset, the actual limit lies equatorward of the $60^{\circ}$ limit, defined by the Quaas regions, for November-January in the Northern Hemisphere

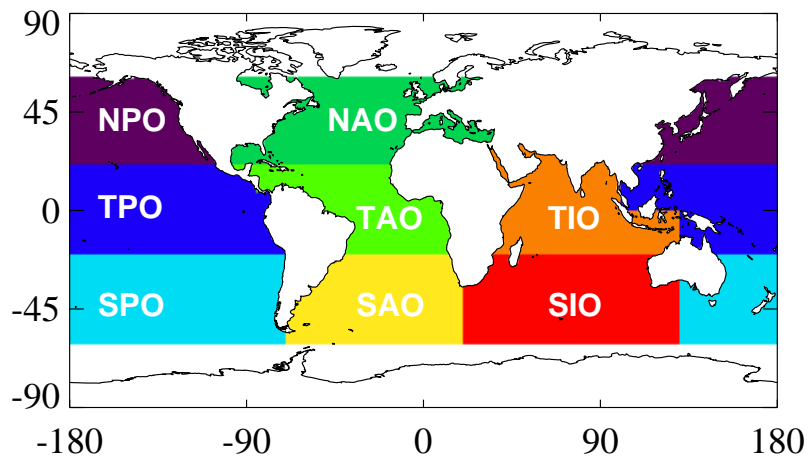

Fig. 8.

$\begin{array}{llll}\text { NAO } & \text { North Atlantic Ocean } & \text { TAO } & \text { Tropical Atlantic Ocean } \\ \text { SAO } & \text { South Atlantic Ocean } & \text { NPO } & \text { North Pacific Ocean } \\ \text { TPO } & \text { Tropical Pacific Ocean } & \text { SAO } & \text { South Pacific Ocean } \\ \text { TIO } & \text { Tropical Indian Ocean } & \text { SIO } & \text { South Indian Ocean }\end{array}$

and for May-July in the Southern Hemisphere, with a maximum discrepancy of $12^{\circ}$.

Due to the changes in AVHRR overpass times, due to changes in orbit over the lifetime of the NOAA satellite, the GACP dataset shows a more complicated story, with an increase in both the size of the truncation of the the high latitude limits of the northern and southern regions, and in the number of months a year so effected. Geogdzhayev et al. (2005) investigated the effect of this orbital drift on the GACP global mean AOD, from the perspective of the total number of samples included in the mean, and the effect of the seasonal cycle on the maximum/minimum latitudes on hemispheric mean AOD. However, an analysis of the effects of the orbital drift on this seasonal cycle was not presented.

Given the band of elevated AOD observed at around $60^{\circ} \mathrm{S}$ in the GACP results, a decreased sampling at high latitudes in the southern ocean regions will result in a lower average AOD for these regions. Thus, the decreasing sampling of the southern part of the SAO, SIO and SPO during the winter over the lifetime of the NOAA satellite can explain the negative AOD trend observed in these regions during the period covered by the GRAPE data. This also explains why no such trend is observed in the GRAPE results, as there is no change in the ERS-2 overpass time (and GRAPE does not see the elevated AOD band around $60^{\circ} \mathrm{S}$ ). It is, however, not possible to disentangle the source of the AOD seasonal cycle seen in the southern regions from the seasonal cycles of the aerosol sources shown in Fig. 10 from the cycle in the sampling seen in Fig. 11, especially as the Chlorophyll- $a$ concentration is derived from satellite measurements that are probably also affected by such sampling biases. 

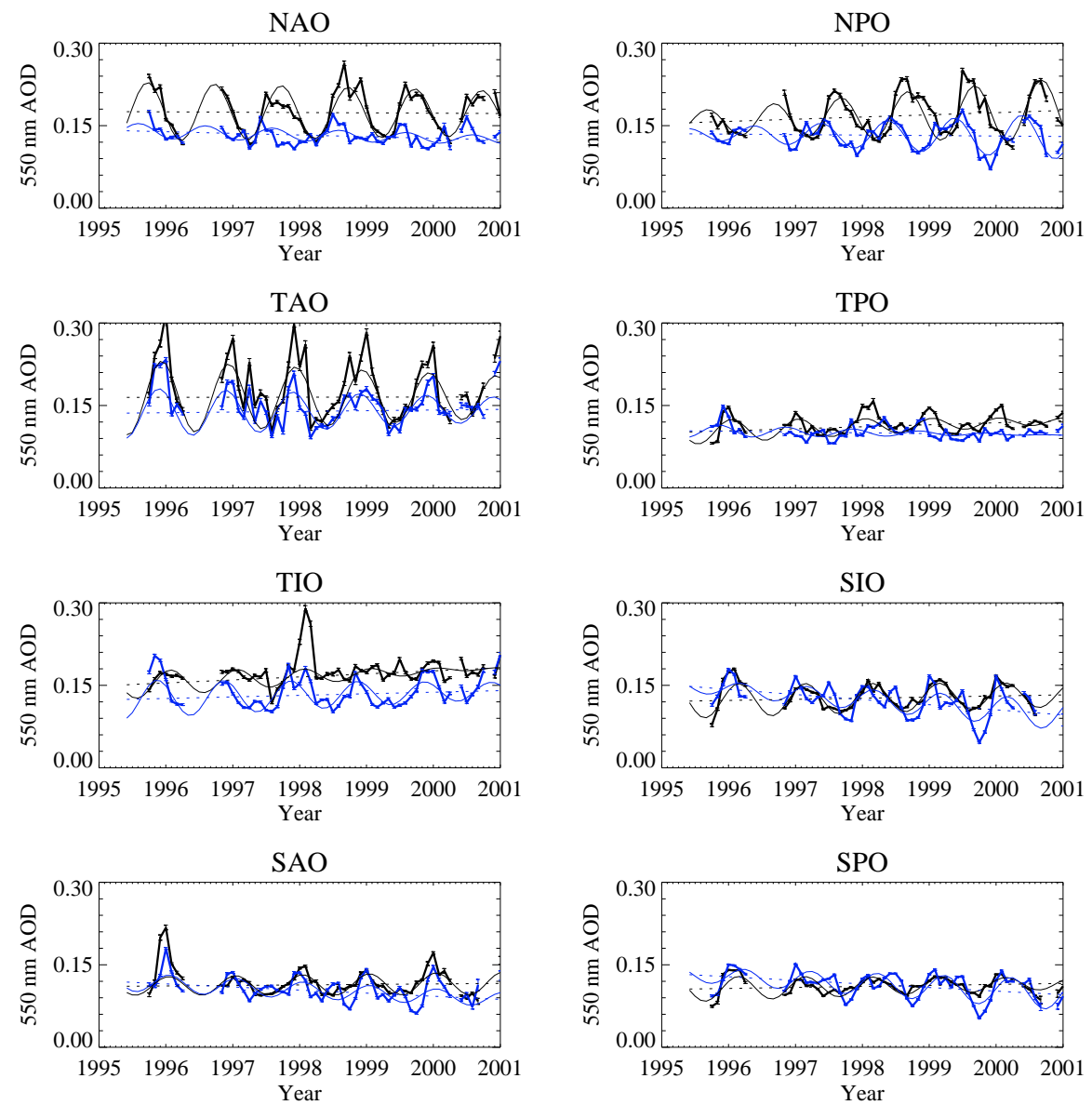

Fig. 9. Regional times series comparison of GRAPE and GACP AOD. Monthly averaged data are given by the thick-solid lines, with GRAPE in black and GACP in blue. Fits to the time-series using Eq. (5) are given by the thin solid lines, and the linear component of these fits are shown by the dotted lines.

The much larger seasonal variation exhibited by the GRAPE data in the northern regions, as well as their discrepancy with the GACP results also warrants further investigation. Although northern regions are also affected by the seasonal sampling biases, it is reasonable to expect a true annual cycle in aerosol loading, because of seasonal changes in both the source strength of the particles, efficiency of longrange transport and aerosol removal processes such as precipitation. Figure 12 shows time-series of monthly mean AOD from AERONET stations which lie along the western edges of the North Atlantic and Pacific Oceans. Although not temporally or spatially coincident with the majority of GRAPE time-series ${ }^{4}$, this cycle is in phase with that seen in the GRAPE data, suggesting that the cycle seen by GRAPE is real. The authors can only speculate about the reasons for the discrepancy in the GACP seasonal cycle, but it is possi-

\footnotetext{
${ }^{4}$ There is insufficient data from appropriately placed AERONET stations to provide a clear seasonal cycle in AOD if we limit the comparison to be within the GRAPE time period.
}

ble that the GACP analysis has flagged heavy aerosol loading events as cloud, or that the retrieval fails in such conditions. Such a hypothesis is supported by the fact that if the GRAPE data is limited to $1 \times 1^{\circ}$ monthly AODs of 1.0 or less, there is no global bias between the two datasets. This could also explain the large positive bias GRAPE shows against GACP in the TIO region.

It is important to emphasise that the analysis undertaken in this section does not provide a validation of the absolute AODs retrieved by GRAPE. Only comparison against a ground truth measurement, such as that undertaken in Sect. 3, can provide such a validation. Some of the features seen in the GRAPE data, such as the very high values of AOD seen in the North Atlantic during the summer (Fig. 5), require further analysis and comparison with more measurements. However, this analysis has provided some confidence in the large-scale variability seen in the GRAPE data. 
(a)

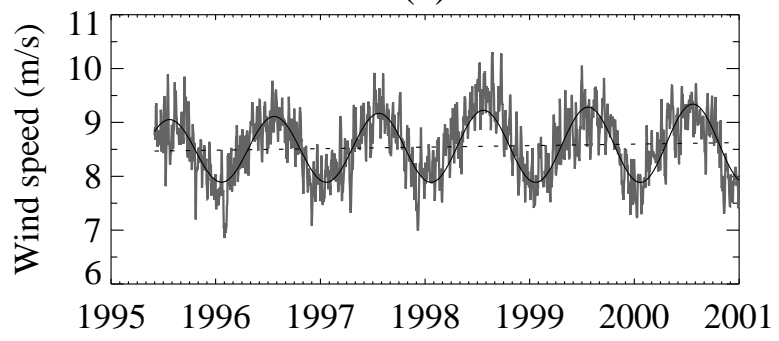

(b)

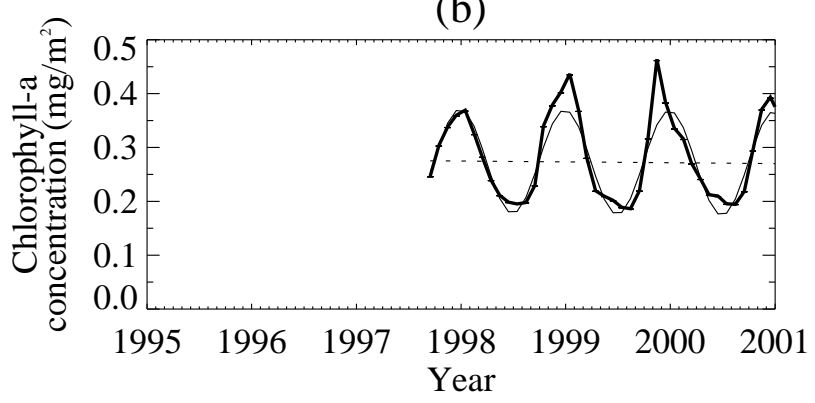

Fig. 10. Time-series of daily mean $10 \mathrm{~m}$ wind speed from ECMWF reanalysis (a) and monthly mean chlorophyll- $a$ concentration from GlobCOLOUR (b) for the southern-most regions defined in Fig 8 (SPO, SAO and SIO). Fits to the time-series using Eq. (5) are given by the thin solid lines, and the linear component of these fits are shown by the dotted lines.

\section{Conclusions}

The GRAPE AOD product over the ocean has been compared against measurements from the AERONET and the GACP AVHRR derived AOD climatology over the ocean. The GRAPE and AERONET AOD measurements show a good correlation of 0.79 . A linear fit between the two data-sets produces a slope of $1.0 \pm 0.1$, however the fit shows GRAPE AODs have a positive bias of $0.08 \pm 0.04$. At higher AODs $(\gtrsim 0.2)$ the comparison also shows a much greater degree of scatter, although this can be attributed to a combination of the random noise in the GRAPE product, sampling differences between the two measurement systems and the effect of systematic errors in the assumed aerosol properties at different locations.

Comparisons between monthly mean ocean AODs between the GRAPE and GACP datasets show reasonable overall agreement between the two datasets, but there are some noticeable discrepancies. The GRAPE dataset displays some anomalously high AODs at high latitudes, which can be attributed to contamination by surface ice: a known problem with the GRAPE dataset. The GRAPE data also show noticeably higher AOD, with discrepancies of 0.2 or more in seasonal averages, in regions affected by transportation of heavy aerosol loading from the continents. Conversely, the band of

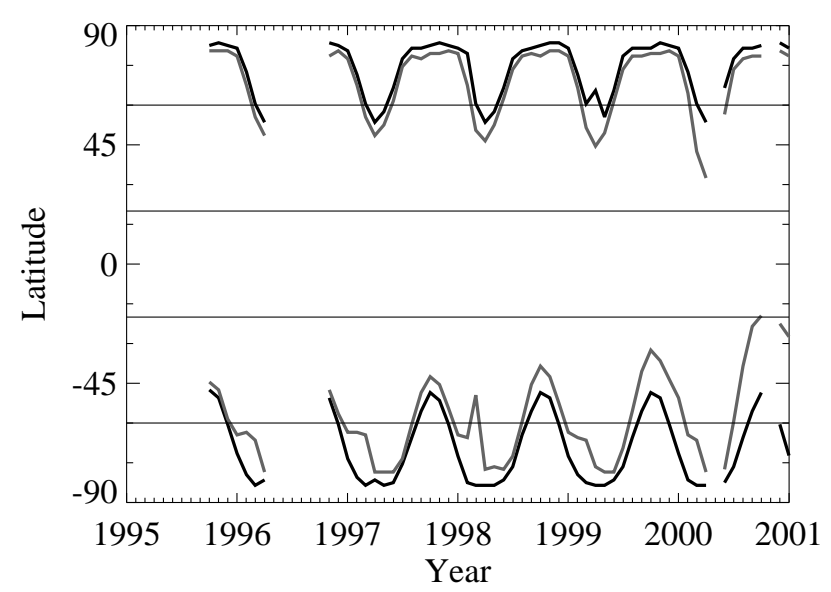

Fig. 11. Time-series of the maximum and minimum latitudes included in the GRAPE (black line) and GACP (grey line) datasets for the period covered by the GRAPE dataset. The thin horizontal lines indicate the north-south boundaries of the regions defined in Fig 8 at $\pm 20^{\circ}$ and $\pm 60^{\circ}$.

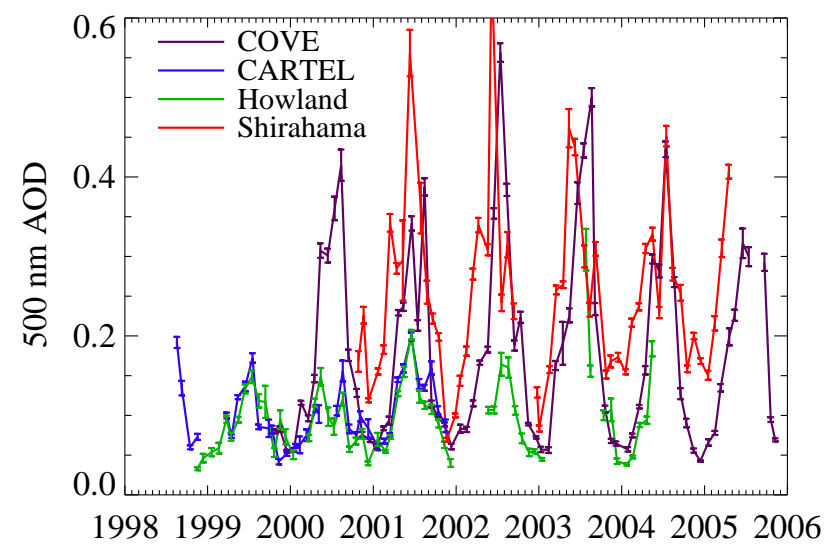

Fig. 12. Time-series of AOD from four AERONET sites along the eastern seaboards of North America (COVE, CARTEL and Howland) and Northern Asia (Shirahama).

elevated AOD seen in the southern oceans in the GACP data is not apparent in the GRAPE data.

Time-series analysis of the GRAPE and GACP monthly means revealed significant differences. Globally, the GRAPE dataset shows a slightly increasing trend in AOD, as opposed to the decreasing trend which has been the headline finding of the GACP dataset (Mishchenko et al., 2007b). The GRAPE dataset shows stronger seasonal variation than is present in the GACP data, particularly in northern oceans (NAO and $\mathrm{NPO}$ ), and also showed significantly higher average AODs in regions affected by continental outflow (the NAO, NPO and TIO in particular). The presence of a strong seasonal cycle in AERONET AODs in the northern ocean regions, which are approximately in phase with that seen in the GRAPE data, 
suggests that a higher proportion of high AOD events are not included in the GACP dataset. This could be due to either over-zealous cloud flagging or the failure of the algorithm at high AOD.

The increasing trend in global AOD seen in the GRAPE data can be attributed to increasing AOD in the NPO, TPO and TIO. All of these regions are subject to aerosol transport from regions which have undergone large scale industrialisation over the past few decades. An increasing trend in aerosol loading is not, therefore, an unexpected result. Conversely, the decreasing trend seen in the GACP data can mostly be attributed to decreasing AOD in the southern ocean regions (SAO, SPO and SIO). This is a surprising result, as the AOD in these regions is dominated by maritime aerosol generated by wind action and the oxidation of DMS generated by the ocean ecosystem. An examination of the latitudinal limits of the two datasets reveals that the decreasing maximum latitude sampled by the AVHRR instrument in winter during the period of comparison could be a possible explanation of this trend.

Overall the GRAPE AOD over ocean dataset has been shown to have a good level of accuracy compared to AERONET AODs, despite a significant positive bias. The potential value of the dataset has been shown by the light this analysis has shed on the long term global aerosol trend suggested by AOD climatologies based on AVHRR measurements.

Due to the limited time period covered by the GRAPE dataset, this analysis cannot be used to draw firm conclusions about long term trends in global and regional AOD. However, the authors believe it amply displays the need for further long-term aerosol datasets. The GlobAEROSOL (Portela et al., 2010) dataset, and the ATSR-2/AATSR dataset produced by Grey et al. (2006) will both provide global AODs covering the range 1995-2007. In addition, the extension of the GRAPE dataset to include all ATSR-2 and AATSR data up to 2009 will become available in 2010 .

Acknowledgements. This work was supported by the Natural Environment Research Council (grant numbers NER/T/S/2001/002, NE/B503933/1 and NE/E011187/1). Additional support was provided by the ESA Data User Element project Globaerosol.

We also greatfully acknowledge the principal investigators of the AERONET sites utilised by this work, as well as NASA Goddard for making AERONET and GACP data available.

Edited by: K. Carslaw

\section{References}

Berk, A., Bernstein, L. S., Anderson, G. P., Acharya, P. K., Robertson, D. C., Chetwynd, J. H., and Adler-Golden, S. M.: MODTRAN cloud and multiple scattering upgrades with application to AVIRIS, Remote Sens. Environ., 65, 367-375, 1998.

Birks A.: Improvements to the AATSR IPF relating to land surface temperature, European Space Agency Technical Note, 2004.
Cox, C. and Munk, W.: Statistics of the sea surface derived from Sun glitter, J. Mar. Res. 13, 198-227, 1954.

Delderfield, J., Llewellyn-Jones, D. T., Bernard, R., de Javel, Y., Williamson, E. J., Mason, I., Pick, D. R. and Barton, I. J.: The Along Track Scanning Radiometer (ATSR) for ERS-1, Proc. SPIE, 589, 114-120, 1986.

Dubovik, O., Holben, B. N., Lapyonok, T., Sinyuk A., Mishchenko, M. I., Yang, P., and Slutsker, I.: Non-spherical aerosol retrieval method employing light scattering by spheroids, Geophys. Res. Lett., 29(10), 1415, 10.1029/2001GL014506, 2002.

Geogdzhayev, I. V., Mishchenko, M. I., Rossow, W. B., Cairns, B. and Lacis, A. A.: Global two-channel AVHRR retrievals of aerosol properties over the ocean for the period of NOAA-9 observations and preliminary retrievals using NOAA-7 and NOAA11 data, J. Atmos. Sci., 59, 262-278, 2002.

Geogdzhayev, I. V., Mishchenko, M. I., Liu, L., and Remer, L.: Global two-channel AVHRR aerosol climatology: Effects of stratospheric aerosols and preliminary comparisons with MODIS and MISR retrievals, J. Quant. Spectrosc. Ra., 88, 47-59, 2004.

Geogdzhayev, I. V., Mishchenko, M. I., Terez, E. I., Terez, G. A. and Gushchin, G. K.: Regional advanced very high resolution radiometer-derived climatology of aerosol optical thickness and size, J. Geophys. Res.-Atmos., 110, D23205, doi:10.1029/2005JD006170, 2005.

Grainger, R. G., Lucas, J., Thomas, G. E., and Ewen, G. B. L.: Calculation of Mie derivatives, Appl. Optics, 43, 5386-5393, 2004.

Grey, W. M. F., North, P. and Los, S.: Computationally efficient method for retrieving aerosol optical depth from ATSR-2 and AATSR data, Appl. Optics, 45, 2786-2795, 2006.

Hess, M., Koepke, P., and Schult, I.: Optical Properties of Aerosols and Clouds: The software package OPAC, B. Am. Meteorol. Soc., 79, 831-844, 1998.

Holben, B. N., Eck, T. F., Slutsker, I., Tanre, D., Buis, J. P., Setzer A., Vermote, E., Reagan, J. A., Kaufman, Y., Nakajima, T., Lavenu, F., Jankowiak, I., and Smirnov, A.: AERONET - A federated instrument network and data archive for aerosol characterization, Remote Sens. Environ., 66, 1-16, 1998.

Holben, B. N., Tanre, D., Smirnov, A., Eck, T. F., Slutsker, I., Abuhassan, N., Newcomb W. W., Schafer J. S., Chatenet B., Lavenu F., Kaufman Y. J., Castle J. V., Setzer A., Markham B., Clark D., Frouin R., Halthore R., Karneli A., O’Neill, N. T., Pietras, C., Pinker, R. T., Voss, K., and Zibordi, G.: An emerging ground-based aerosol climatology: Aerosol optical depth from AERONET, J. Geophys. Res.-Atmos., 106, 12067-12097, 2001.

von Hoyningen-Huene, W., Freitag, M. and Burrows, J. B.: Retrieval of aerosol optical thickness over land surfaces from topof-atmosphere radiance, J. Geophys. Res.-Atmos., 108, 4260, doi:10.1029/2001JD002018, 2003.

Ichoku, C., Chu, D. A., Mattoo, S., Kaufman, Y. J., Remer, L. A. Tanre, D., Slutsker, I. and Holben, B.N.: A spatio-temporal approach for global validation and analysis of MODIS aerosol products, Geophys. Res. Lett., 29, 8006, doi:10.1029/2001GL013206, 2002.

IPCC: Climate Change 2007: The physical science basis. Contribution of Working Group I to the Fourth Assessment Report of the Intergovernmental Panel on Climate Change, edited by: Solomon, S., Qin D., Manning M., Chen Z., Marquis M., Averyt K. B., Tignor M., and Miller H. L., Cambridge University 
Press, Cambridge and New York, 2007.

Jin, Y., Schaaf, C. B., Woodcock, C. E., Gao, F., Li, X., Strahler, A. H., Lucht, W., and Liang, S.: Consistency of MODIS surface BRDF/Albedo retrievals: 1. Algorithm performance, J. Geophys. Res.-Atmos., 108, 4158, doi:10.1029/2002JD002803, 2003.

Kinne, S., Lohmann, U., Feichter, J., Schulz, M., Timmreck, C., Ghan, S., Easter, R., Chin, M., Ginoux, P., Takemura, T., Tegen, I., Koch, D., Herzog, M., Penner, J., Pitari, G., Holben, B., Eck, T., Smirnov, A., Dubovik, O., Slutsker, I., Tanre, D., Torres, O., Mishchenko, M., Geogdzhayev, I., Chu, D. A., and Kaufman, Y.: Monthly averages of aerosol properties: A global comparison among models, satellite data, and AERONET ground data, J. Geophys. Res.-Atmos., 108, 4634, doi:10.1029/2001JD001253, 2003.

Liu, L., Mishchenko, M. I., Geogdzhayev, I., Smirnov, A. Sakerin, S. M., Kabanov, D. M., and Ershov, O. A.: Global validation of two-channel AVHRR aerosol optical thickness retrievals over the oceans. J. Quant. Spectrosc. Ra., 88, 97-109, 2004.

Lohmann, U. and Feichter, J.: Global indirect aerosol effects: a review, Atmos. Chem. Phys., 5, 715-737, doi:10.5194/acp-5-7152005, 2005.

Martonchik, J. V., Diner, D. J., Crean, K. A. and Bull, M. A.: Regional aerosol retrieval results from MISR, IEEE T. Geosci. Remote, 40, 1520-1531, 2002.

Mishchenko, M. I., Geogdzhaev, I. V., Cairns, B., Rossow, W. B., and Lacis, A. A.: Aerosol retrievals over the ocean by use of channels 1 and 2 AVHRR data: sensitivity analysis and preliminary results, Appl. Optics, 38, 7325-7341, 1999.

Mishchenko, M. I. and Geogdzhaev, I. V.: Satellite remote sensing reveals regional tropospheric aerosol trends, Opt. Express, 15, 7423-7438, 2007.

Mishchenko, M. I., and I. V. Geogdzhaev, Rossow, W. B., Cairns, B., Carlson, B. E., Lacis, A. A., Liu, L., and Travis, L. D.: Long-term satellite record reveals likely recent aerosol trend, Science, 315, 1543, doi:10.1126/science.1136709, 2007.

Mutlow, C. T., Murray, M. J., Bailey, P., Birks, A. R., and Smith, D. L.: ATSR-1/2 user guide issue 1, ESA User Guide, 1999.

Myhre, G., Stordal, F., Johnsrud, M., Ignatov, A., Mishchenko, M. I., Geogdzhayev, I. V., Tanré, D., Deuzé, J.L., Goloub, P., Nakajima, T., Higurashi, A., Torres, O., and Holben, B. N.: Intercomparison of Satellite Retrieved Aerosol Optical Depth over the Ocean, J. Atmos. Sci., 61, 499-513, 2004.

Myhre, G., Stordal, F., Johnsrud, M., Diner, D. J., Geogdzhayev, I. V., Haywood, J. M., Holben, B. N., Holzer-Popp, T., Ignatov, A., Kahn, R. A., Kaufman, Y. J., Loeb, N., Martonchik, J. V., Mishchenko, M. I., Nalli, N. R., Remer, L. A., SchroedterHomscheidt, M., Tanré, D., Torres, O., and Wang, M.: Intercomparison of satellite retrieved aerosol optical depth over ocean during the period September 1997 to December 2000, Atmos. Chem. Phys., 5, 1697-1719, doi:10.5194/acp-5-1697-2005, 2005.

Pinnock, S., D'Andon, O. F., and Lavender, S.: GlobColour - A precursor to the GMES marine core service ocean colour Thematic Assembly Centre, ESA Bulletin, European, Space Agency, 132, 42-49, 2007.
Portela, O., Thomas, G. E., Poulsen, C. A., and Grainger, R. G.: GlobAEROSOL product user guide, online available at: http: //www.globaerosol.info/docs/globaer_pug_v1p1.pdf, last access: 22 March 2010.

Press, W. H., Teukolsky, S. A., Vettering, W. A. and Flannery, B. P.: Numerical recipes in Fortran 77, Second Edition. Cambridge Univ. Press, UK, 1992.

Quaas, J., Boucher, O., Bellouin, N., and Kinne, S.: Satellite-based estimate of the direct and indirect aerosol climate forcing, J. Geophys. Res.-Atmos., 113, D05204, doi:10.1029/2007JD008962, 2008.

Remer, L. A., Kaufman, Y. J., Tanre, D., Mattoo, S., Chu, D. A., Martins, J. V., Li, R. R., Ichoku, C., Levy, R. C., Kleidman, R. G., Eck, T. F., Vermote, E. and Holben B. N.: The MODIS aerosol algorithm, products, and validation, J. Atmos. Sci., 62, 947-973, 2005.

Rodgers, C. D.: Inverse methods for atmospheric sounding: Theory and practice, World Scientific, Singapore, 2000.

Smirnov, A., Holben, B. N., Sakerin, S. M., Kabanov, D. M., Slutsker, I., Chin, M., Diehl, T, L., Remer, A., Kahn, R., Ignatov, A., Liu, L., Mishchenko, M., Eck, T. F., Kucsera, T. L., Giles, D., and Kopelevich, O. V.: Ship-based aerosol optical depth measurements in the Atlantic Ocean: Comparison with satellite retrievals and GOCART model, Geophys. Res. Lett., 33, L14817, doi:10.1029/2006GL026051, 2006.

Smith, D. L., Mutlow, C.T. and Rao, C. R. N.: Calibration Monitoring of the Visible and Near-Infrared Channels of Along-Track Scanning Radiometer-2 (ATSR-2) using Stable Terrestrial Sites, Appl. Optics, 41, 515-523, 2002.

Stamnes, K. Tsay, S. C., Wiscombe, W., and Jayaweera, K.: Numerically stable algorithm for discrete ordinate method radiative transfer in multiple scattering and emitting layered media, Appl Optics, 27, 2502-2509, 1988.

Stowe, L. L., Jacobowitz, H., Ohring, G., Knapp, K. R., and Nalli, N. R.: The Advanced Very High Resolution Radiometer (AVHRR) Pathfinder Atmosphere (PATMOS) climate dataset: Initial analysis and evaluations, J. Climate, 15, 1243-1260, 2002.

Thomas, G. E., Carboni, E., Sayer, A. M., Poulsen, C. A., Siddans, R., and Grainger, R. G.: Oxford-RAL Aerosol and Cloud (ORAC): Aerosol retrievals from satellite radiometers, in: Aerosol remote sensing over land, edited by: Kokhanovsky, A. A. and de Leeuw, G., Springer, Berlin, 2009a.

Thomas, G. E., Poulsen, C. A., Sayer, A. M., Marsh, S. H., Dean, S. M., Carboni, E., Siddans, R., Grainger, R. G., and Lawrence, B. N.: The GRAPE aerosol retrieval algorithm, Atmos. Meas. Tech., 2, 679-701, doi:10.5194/amt-2-679-2009, 2009b.

Veefkind, J. P., de Leeuw, G., and Durkee, P. A.: Retrieval of aerosol optical depth over land using two-angle view satellite radiometry during TARFOX, Geophys. Res. Lett., 25, 3135-3138, 1998.

Watts, P. D., Allen, M. R., and Nightingale, T. J.: Wind speed effects on sea surface emission and reflection for the Along Track Scanning Radiometer, J. Atmos. Oceanic Technol., 13, 126-141, 1996.

Watts, P. D., Mutlow, C. T., Baran, A. J., and Zavody, A. M.: Study on cloud properties derived from Meteosat Second Generation observations, EUMETSAT ITT no. 97/181, 1998.

Yu, H., Kaufman, Y. J., Chin, M., Feingold, G., Remer, L. A., Anderson, T. L., Balkanski, Y., Bellouin, N., Boucher, O., Christopher, S., DeCola, P., Kahn, R., Koch, D., Loeb, N., 
Reddy, M. S., Schulz, M., Takemura, T., and Zhou, M.: A review of measurement-based assessments of the aerosol direct radiative effect and forcing, Atmos. Chem. Phys., 6, 613-666, doi:10.5194/acp-6-613-2006, 2006.
Zhao, T. X.-P., Laszlo, I., Guo, W., Heidinger, A., Cao, C., Jelenak, A., Tarpley, D., and Sullivan, J.: Study of long-term trend in aerosol optical thickness observed from operational AVHRR satellite instrument. J. Geophys. Res.-Atmos., 113, D07201, doi:10.1029/2007JD009061, 2008. 